\title{
Being smarter about space: drawing lessons from spatial science
}

\section{Ate Poorthuis}

Humanities, Arts, and Social Sciences

Singapore University of Technology and Design

\author{
Matthew Zook \\ Department of Geography \\ University of Kentucky
}

Published as: Poorthuis, A. \& M. Zook. (2019). Being smarter about space: drawing lessons from spatial science. Annals of the American Association of Geographers. [Online First] https://doi.org/10.1080/24694452.2019.1674630

\section{Abstract}

Smart technology - in its many facets - is often critiqued within Geography in ways that parallel the critiques of quantitative geography in the 1960s and GIScience in the 1990s. In this way, both the development on 'smart' technology itself and its criticisms are the latest chapter in a long-standing disciplinary debate around quantification and technology. We re-evaluate this history and argue that quantitative methodology and its theoretical critiques are not as incompatible as often claimed.

To illustrate how we might address this apparent tension between theory and quantitative methods we review how both approaches conceptualize one of Geography's core concepts: space, and highlight opportunities for symbiosis. Although smart technologies can further orthodox positivist approaches, we argue that the actual practice is more nuanced and not necessarily absolute or totalizing. For example, recent computational work builds upon critical geographic theories to analyze and visualize topological and relational spaces, relevant to topics such as gentrification and segregation. The result is not a Geography in which smart technology and algorithms remove the need for human input but rather a rejoinder in line with the recent resurgence of a critical quantitative geography. In short, a Geography where social theory and the human intellect play a key role in guiding computational approaches to analyze the largest, most versatile and relevant datasets on social space that we have ever had.

\section{Keywords}

Smart technology, space, spatial science, GIScience, geocomputation 


\section{Opportunities of smart technologies}

It has been a decade since Chris Anderson published his polemic Wired article on big data and the subsequent "end of theory" (Anderson 2008). In the intermediate years, our discipline has written extensively on the theoretical, methodological and practical implications of a broad range of new technologies (using interconnected monikers varying from geoweb and VGI to big data, and in this issue, labeling such technology as 'smart'), perhaps even heralding in a 'digital turn' within the discipline (Ash, Kitchin, and Leszczynski 2018). Much attention has been paid to the socio-spatial implications of digital technology on our everyday lives (e.g. Kitchin and Dodge 2011) and, in the context of smart specifically, the effect on urban governance (Leszczynski 2016; Shelton, Zook, and Wiig 2015). Building on this foundation, we focus instead on the methodological implications of smart technology for Geography. This too has received ample attention recently and is sometimes labeled a new 'quantitative revolution' (Wyly 2014) - one that is not necessarily welcomed by all. These quantitative approaches, reinvigorated by access to new computing technology and datasets, have been critiqued from (social) theory in similar ways as GIScience in the 1990s and the earlier onset of spatial science in 1960s. Thus, both the current 'smart' technology itself and the critiques leveled against it are but the latest chapter in a long-standing disciplinary debate around quantification and technology.

Using one of Geography's core concepts - space - and drawing from the spatial science turn of the 1960s, we highlight the significant potential for synthesis and symbiosis between quantitative methodology and geographical theory. In short, we argue that while new technologies might further an orthodox positivist ontology and epistemology, they also can enable the analysis of the rich, intricate fabric of space in myriad ways that are quantitative, but are not necessarily absolute or totalizing. In particular, we seek to connect the ways the quantitative movement of the 1960s theorized space - including acknowledging the limitations of an Euclidian approach (Bunge, 1966; Harvey, 1969) - with the social theories used in theoretical geography today.

Geography as a discipline is at a unique moment in its relationship with 'smart' technologies. We use the 'smart' label here as an umbrella term to indicate the onset of new computational technologies enabling every larger, faster, more exhaustive and varied datasets about social life to be created and collected ('big data', cf. Kitchin and McArdle (2016)) as well as the associated technologies (e.g. cloud computing; machine learning, etc.) allowing for the analysis of such data (Leszczynski 2016; Shelton, Zook, and Wiig 2015). If Geography chooses to engage with smart technologies, it is essential that it is not constrained to just extending existing Geographic Information Systems, city dashboards, or sophisticated governance control rooms. Nor should we simply let software giants like ESRI and IBM push geographic software development. While creating useful tools, they are ultimately responding to market demands, not the pursuit of 
science. Moreover, we should not take a backseat to other disciplines entering the 'smart' arena: physics, computer science and complexity science all have important contributions to make but are coming from significantly different perspectives than Geography. Rather, we should learn from our experience with the spatial science turn to leverage the onset of smart technologies into opportunities to build a tighter integration between geographic theory and quantitative methodology.

\section{Evolving theories of space}

Traditionally, space was treated as a container or geometric system holding the object(s) under study and allowed users to lay an abstract plane over the Earth's surface. In most cases this abstract plane is simply a two-dimensional Euclidean (or, after the $17^{\text {th }}$ century, Cartesian) space with $x$ - and $y$-axes useful for describing location. Examples range from Ptolemaios (AD 90 -168) pinpointing all then-known places within his atlas, Geographia, or the regional geography of the pre-war era (e.g. Hartshorne 1939) that tasked itself with locating cities, countries and people. Importantly, objects within such a space are generally considered to be completely independent of each other. Their only relationship is defined through measuring their distance to other objects.

In the second half of the $20^{\text {th }}$ century, geographers - and social scientists in general critiqued this conceptualization of space as hampering the actual understanding of social (and spatial) processes. For example, Merleau-Ponty's (Merleau-Ponty [1945] 2012) phenomenological analysis of space (forbearing the sub-discipline of humanistic geography) argues for a primordial situated space that is neither object nor subject or a space where people and things are no longer independent of each other. Likewise, Lefebvre's well-known argument completely breaks away from the notion of space as a container, asserting explicitly that space is socially produced and non-Euclidean (Lefebvre 1991). Moreover, space as a product is never final but rather produced, consumed and reproduced in a never-ending and iterative process. As such, space cannot simply be thought of as something finished - a static object of study. To understand space, we must study the process of space.

In this way, Geography has moved far from the Euclidean conceptualization of space as a simple container and instead engages with space that is produced and reproduced in a continuous fashion. This production of space is messy - consisting of many interconnected and contradictory layers of everyday social life - such as emblemized by Massey's (1994) walk through Kilburn in which she argues that places do not just have one singular identity, or one sense of place. More recently, geography has seen a renewed interest in a relational understanding of space (Boggs and Rantisi 2003; Jones 2009) which foregrounds actors (or 
actants) within space and how their relationships continuously make and remake space (Brenner, Madden, and Wachsmuth 2011).

\section{Continued reliance upon Euclidean spatial ontologies}

This review highlights the complexity of the social theories of space used by Geographers and yet, we must also note the continued reliance upon a Euclidean definition of space within quantitative research. Making this dependence even more remarkable are the convincing critiques of its problematic nature. First, space as an absolute container enables a reductionist, totalizing perspective on society. Harvey $(1996,284)$ is very clear about the consequences of this perspective: 'to produce one dominant cartographic image out of all this multiplicity is a power-laden act of domination'. In other words, a Euclidean perspective on space is just one of many views on space. A single, true representation of space does not exist, and proceeding otherwise neglects the heterogeneity of social life. Second, space as an absolute container can enable a static, immutable perspective on society. The Euclidean container cannot change itself - it is pre-existing after all - and thus might direct our attention to static patterns and less so to social processes. Third and finally, space as an absolute container focuses on the location of independent objects and ignores the relative and relational connections between people, institutions and other actors that together make up social space.

This contrast begs the question of why there is such a disconnect between theoretical and quantitative work on space within Geography. Why are we still content with the spatial constraints of traditional desktop GIS software rather than developing Lefebvrian GIS or Masseyian Mapping Software? In sum, why are we still actively using a quantitative methodology that is inherently and ontologically incompatible with how we (theoretically) think about society and space? To be clear, we are not calling for an abolishment of Euclidean space altogether as its conceptualization is useful for many applications. Instead, our point is that it is but one of many possible conceptualizations, and our reliance on it shapes our understanding of the world.

While there are many historical factors beyond our simple summary here (cf. Schuurman 2006) we use this understanding to document a moment during the 1950s and 1960s when competing conceptualizations were in play including the surprisingly sophisticated use of relational spatial ontologies in early work by spatial scientists. We suggest that ultimately, the emergence of the personal computer and desktop GIS in the 1980s helps solidify a standard for quantitative analysis of space that leaves less room for alternative conceptualizations. We further contend that this history can provide useful guidance in how the discipline approaches smart technologies today. This is similar to the impetus behind the field of geocomputation as Gahegan $(1999,203)$ put it: 'GIS saw to it that geographers became the slaves of the 
computer, having to adopt the impoverished representational and analysis capabilities that GIS provided.' It is our contention that a similar impoverishment of space need not, and should not, occur in the present day.

\section{Developing Spatial Science}

Amidst an academic landscape in which Geography was increasingly threatened with departments closed down, a re-orientation towards Spatial Science began in the 1950s. As a spatial science, the goal was not to describe things within space, but rather to find general laws and theories explaining space. With this, space shifted from just a container or handy filing system to become the very nexus of geographic research. It is sometimes argued that this 'revolution' re-enforced the use of an absolute or 'naïve' spatial ontology within Geography (e.g. Cresswell 2013, 103-5). However, the centrality of space to the new spatial science, meant that many of its proponents and the contemporarily-cited works of the decade grappled explicitly with the limitations of Euclidean space. For example, in his standard work on spatial science, Harvey (1969, 210-11) writes:

'Given the philosophy of absolute space, the metric in that space must remain isotropic and constant. [...] Relations between objects on the earth's surface, the extent of areal units, and so on, could be measured by the direct extension of Euclidean concepts of space and distance to the surface of a sphere. [...] This view is no longer generally acceptable. Thus Watson (1955) has pointed out that distance can and must be measured in terms of cost, time, social interaction and so on, if we were to gain any deep insight in to the forces moulding geographic patterns. [...] The metric is thus determined by activity and by the influence of objects. Such a concept of distance is purely relative.'.

Importantly, Harvey was not isolated in this spatial thinking. Alternative, relational conceptualizations of space (and the accompanying operationalization through mathematical topology and graph theory) were en vogue well before Harvey's observation. We highlight two particularly noteworthy strains of this relational thinking within spatial science. The first removes some of the limitations of Euclidean space by looking at non-Euclidean measures of distance (e.g. perception, cost, etc.). The second strain is more explicit and forgoes twodimensional space altogether in favor of graph theory and network analysis.

\section{Non-absolute conceptualizations of space}

Some of the earliest traces of geographers using a non-absolute space are the so-called 'potential maps' of the 1950s. Here, geographers (and physicists-turned-geographers, see Barnes and Wilson (2014)) borrow heavily from physics and use the concept of 'potential' to study spatial phenomena such as population distribution and transportation accessibility (Stewart and Warntz 1958). In a potential model, the value of a point is determined by its connections - based on variables such as accessibility or economic pricing - to all other points. 
For example, Harris (1954) uses it to calculate the market potential in the US, making it an implicitly relational, not territorial concept.

The ideas within potential models were extended to map transformation (Hägerstrand 1957; Tobler 1963) used this not to project the three-dimensional earth on a two-dimensional plane but rather to transform Euclidean space to a more phenomenon-appropriate form. Hägerstrand (1957) uses an innovative azimuthal projection centered on Asby, Sweden that is scaled logarithmically to show that physical distance is not the most important determinant in understanding migration (see Figure 1a). Tobler (1963) extends this innovation and argues maps can be transformed based on other variables as well (similar to cartograms) and can even be used to (quantitatively) compare and contrast these different spaces. Building from Christaller's theoretical model of central places (which assumes an underlying isotropic space) Bunge (1966) and Getis (1963) demonstrated it was possible to transform space based on population and income levels to better 'fit' the real-world empirical application (see Figure 1b).

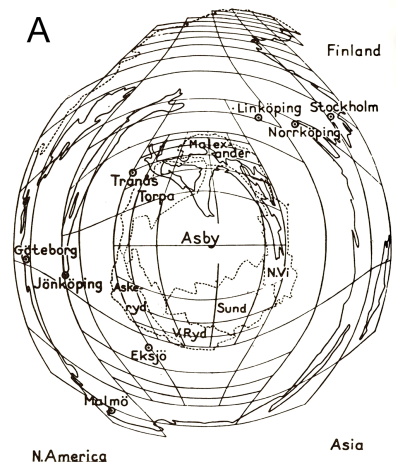

B

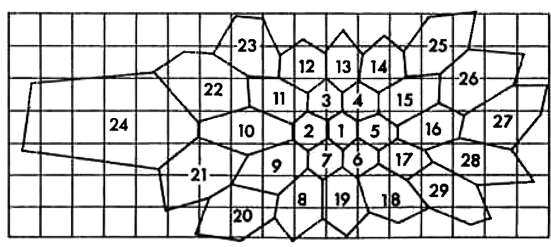

Figure 9.30. An approximation of a Christaller solution applied to an area of disuniform rural population.

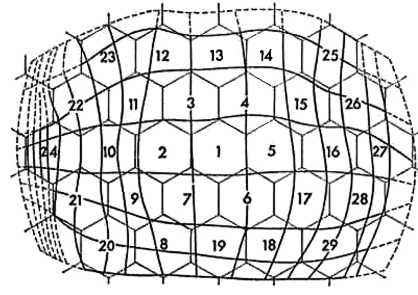

Figure 9.31. Map transformed into uniform density. Note: The reader might benefit from mental comparison of the two base maps in Figures 9.30 and 9.31, i.e., a comparison of the

Figure 1. Examples of non-absolute space in Geography from the 1950-1960s. A. Hägerstrand's (1957) use of an azimuthal projection centered on Asby that is scaled logarithmically to illustrate that physical distance is not the most important determinant in understanding migration; B. Bunge's (1966) transformation of Christaller's hexagonal space based on the underlying population.

In methodologically-similar approaches, other spatial scientists studied cognitive spaces to better understand how space is actually perceived. In the same way as Hägerstrand transformed physical distance, the perception of space and distance can be drawn, compared and analyzed - eventually kickstarting an entire subdiscipline of behavioral geography (Golledge 1977; Gould and White 1974). One technique used in spatial science to deal with these new spaces is multidimensional scaling (MDS) in which objects are defined by the strength of their relationship to other objects rather than treated as independent. In cognitive mapping, this can be used to show cognitive distortion (Golledge, Rivizzigno, and Spector 1976) 
but can be equally useful in mapping other spaces, ranging from time-space (Marchand 1973) to cost space (Forer 1978), and even 'marriage' space (Kendall 1971). In short, far from only only using Euclidean spatial ontologies, this period represents an intense engagement with spatial theories, including relational space. As Gatrell $(1981,151)$ argues "The proliferation of different concepts of space has placed new demands [...] for techniques to give tangible expression to such concepts. The realization that a relative, rather than absolute, view of space may offer a more appropriate context within which to map geographical objects [...]"

\section{Experimenting with graph theory}

The most explicit use of relational space, however, can perhaps be found in the adoption of graph theory in which space does not pre-exist at all but is defined through its constituent parts. These parts consist of nodes (also called vertices) and the edges (or ties or links) between them. Both vertices and edges can have certain characteristics indicating, for example, the strength of a tie or the size of a node. Together, these nodes and their ties form a network, which is why the term 'network analysis' is often used to refer to this type of analysis.

Arguably the first explicit use of graph theory in Geography was Garrison's (1960) study of the new US Interstate highway system. Garrison searched for a way to analyze these new highways as a system and tentatively identified graph theory as a solution. Nystuen and Dacey (1961) took Garrison's first pass a step further and applied graph theory to the problem of regionalization. Interested in the concept of the nodal region - a dominant central place or nodal point with surrounding hinterland - they argued that graph theory was well suited to express and analyze this hierarchy of cities or nodes. In an empirical study that could be labeled 'novel' even today, they used the number of direct long-distance telephone messages between cities in and around Washington State to build a weighted network. In so doing, and without explicitly expressing this, they projected a two-mode (person-city) network to a one-mode (citycity) network and used weighted degree centrality to detect the 'nodal structure' within this network - forty years before the oft-cited Barrat et al. (2004) formalized weighted degree centrality in the same way. A final note should be made of Hemmens' 1966 dissertation on 'the spatial structure of urban activities' (Hemmens 1966) in which he used trip data to determine 'linkages' between different zones in Buffalo, NY. He showed how zones cluster together in distinct groups that are - very importantly - not necessary spatially contiguous. A conclusion that would have been impossible to derive from the common, topographical perspective on spatial clusters.

After the initial wave of work from American geographers, British geographers took over the baton with Haggett and Chorley publishing a comprehensive standard work on 'Network Analysis in Geography' (Haggett and Chorley 1969). It spends over 300 pages discussing 
topological structures and graph theory and their application to geographic problems. Even in the 1970s, network analysis still formed an important part of British geography with Peter Taylor's (1977) Quantitative Methods in Geography - an introduction to spatial analysis for undergraduate students - discussing graph theory in its very first pages.

Despite this early work, by and large, graph theory and topological space dropped off the quantitative geography radar during the 1980 s, not to re-appear with any strength until the $21^{\text {st }}$ century. Perhaps coincidentally, this decline paralleled the appearance of the personal computer in academic research and the standardization of tools - most notably ESRI's launch of the ARC/INFO GIS in the early 1980s. While these technologies heightened the speed and ease of quantitative analysis, they also constrained the possibility frontier. After all, using off-theshelf software means accepting the techniques, methods and ontologies pre-programmed in the software and potentially forgoing other approaches (cf. Rey 2009). A simple example of the power of the affordances and standards offered by software is the de facto standard spatial data format - the Shapefile - which, crucially for this article, has no awareness of topology. Instead it uses a topographical ontology, where each object is defined by its exact location in a Euclidean container. Thus, the narrowing of quantitative research within Geography might be seen as an outcome of software-sorting (cf. Graham 2005) in which the code and algorithms embedded in our tools shape our methods and ontologies.

\section{Assembling a 'smart' symbiosis for Geography today}

This short exposition of different spatial ontologies in spatial science illustrates the historical interest in and potential for non-Euclidean spaces within quantitative geography. As Geography grapples with how best to incorporate smart technologies in our research praxis, this history and the ways in which some spatial ontologies were elevated and others dismissed is particularly germane. One could imagine adoption of new technologies leading to an extension of conventional GIS software or being applied to urban dashboards and governance. As such, smart technology and data might enhance these systems by virtue of its data covering a larger part of the population and social life, or even enable the adoption of participatory frameworks as is often discussed or foreshadowed in the discourse around smart cities (Stratigea, Papadopoulou, and Panagiotopoulou 2015), but this would not entail a more radical reimagining of such software and methods. In our assessment, this would be a disappointing outcome.

Instead, we posit that these new technologies could usefully catalyze a more comprehensive reanchoring of computational geography to the theoretical foundations of our discipline, in line with the calls for critical quantitative geography made in the past decade (Kwan and Schwanen 2009; Wyly 2011). In the recent discourse around critical GIS (O'Sullivan, Bergmann, and 
Thatcher 2018; Thatcher, Bergmann, and O'Sullivan 2018) we find several contributions arguing for a re-imagining of GIS (Gahegan 2018) and an opening up to different spatial ontologies (Bergmann and O'Sullivan 2018). Likewise, the field of geocomputation (Cheng, Haworth, and Manley 2012) brings together geography and computer science and, in Gahegan's (1999) reading, is specifically meant to alleviate the 'shortcomings' of GIS. Arribas-Bel and Reades (2018) similarly posit geocomputation as a separate tradition focused on what the intersection of geography and computing makes possible. In short, if we are to enter a smart era of Geography, we would do well to heed these calls in earnest and use the unique opportunity offered by new technologies and data sources to radically reimagine how we think geographically through computation (methods); (new) data; and software. Luckily, against this backdrop of new technologies, there are several examples of recent work that reimagines quantitative geography across these three dimensions.

\section{Reimagining Methods, Data and Software}

In terms of methods, similar to the experiments with different 'types' of distance and relations and Multidimensional Scaling, geographers have started to use Self-Organizing Maps (SOM). SOM are a type of neural network and thus need to be 'trained'. This training is computationally intensive so this (similar to other machine and deep learning methods) is a methodological approach enabled by the affordances of new, smart technology. Spielman and Thill (2008) use SOM to understand the complex 'attribute space' of urban neighborhoods in New York (see Figure 2a). The same technique can be expanded to understand spatial processes such as neighborhood change (Delmelle 2017). Similarly, other authors have explicitly experimented with relational spaces in quantitative work. For example, Shelton (2018) uses a relational perspective on poverty and constructs networks of relations between rental properties concentrated areas of poverty and their owners, which are often located in other neighborhoods - showing that poverty itself is networked process (Figure 2b; see also Elwood et al, 2017). 


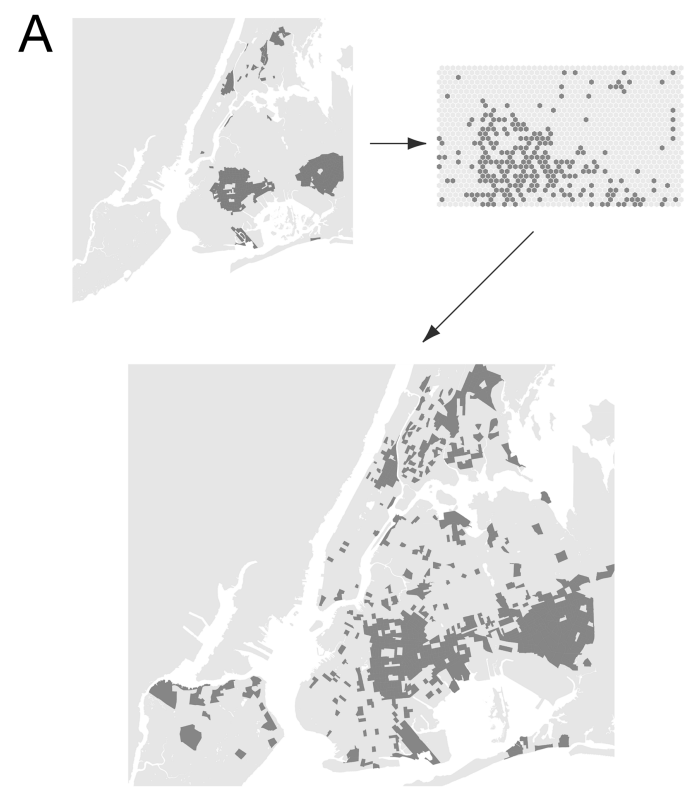

B

Racially/Ethnically Concentrated Areas of Poverty

Racially/Ethnically Concentrated Areas of Relative Poverty

Racially/Ethnically Concentrated Areas of Relative Affuence

Racially/Ethnically Concentrated Areas of Affluence

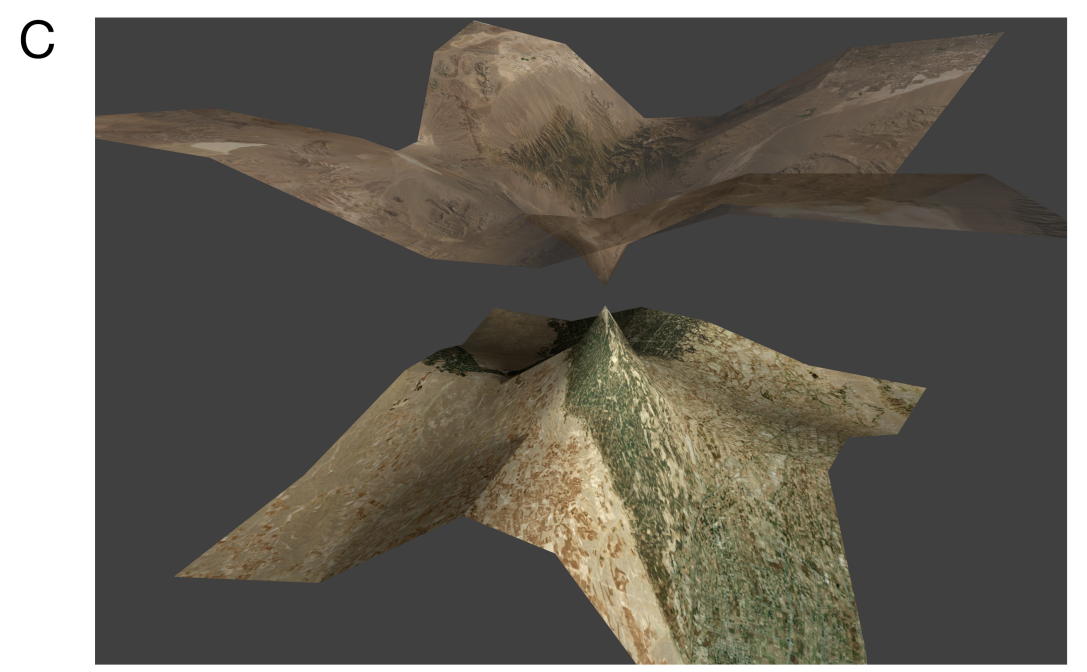

Figure 2. Recent examples of non-absolute space in Geography. A. Spielman and Thill (2008) use Self Organizing Maps (SOM) to understand the complex 'attribute space' of urban neighborhood. Here they show how SOM can be used to select neighborhoods that are similar to the input selection (upper-left corner); B. Shelton (2018) uses a relational perspective to show that property owners of rental housing in concentrated areas of poverty often live outside those areas themselves; C. Lally and Bergmann (forthcoming) use their software 'enfolding: $a$ prototype Geographical Imagination System (GIS)' ${ }^{1}$ to create a 'wormhole' that connects Creech Air Force Base in Nevada, from which drones are operated, with the location of a US drone strike in Marjah, Pakistan.

\footnotetext{
${ }^{1}$ https://github.com/FoldingSpace/enfolding
} 
New technologies, such as smart phones, and new social practices that come along with these technologies produce new types of finely grained data. These datasets range from social media data and cell phone records to sensor data and smart card transactions and help to further enable the aforementioned reimagination. For example, Shelton and Poorthuis (2019) use social media data to redraw Atlanta's neighborhood boundaries based on the spatial networks of its inhabitants and contrast this with the official administrative and territorial boundaries. Boeing (2018) uses OpenStreetMap data to perform an network analysis of street networks in every US city at different levels of scale, while Wachsmuth and Weisler (2018) use data derived from Airbnb to analyze the effect of short-term rentals of gentrification in New York.

Finally, we have seen a major resurgence of open-source geographic software, ranging from the desktop GIS platform QGIS (QGIS Development Team 2019), to ecosystems around the $p y S A L$ library (Rey and Anselin 2010) for Python and the sf (Pebesma 2018) library for R - allowing geographers to more creatively develop and use research tools. Many of such software packages contain relational concepts in addition to Euclidean or topographical tools opening up possibilities for adoption of diverse theories of space. Moreover, the modular approach of open-source software provides a pathway for reconnecting geography with network analysis, as network analysis libraries for the Python and R ecosystems exist parallel to their spatial counterparts. Ironically, network analysis has paid considerable attention to the spatial layout and visualization of network graphs in recent years - so far without input from Geography. As an example, building on top of the projection software proj.4, Bergmann and O Sullivan (2017) explore how Tobler's ideas for applying map projections to different spaces can be implemented in modern geographic software. Although their suggested software hyperproj is still only conceptual - an actual implementation isn't far-fetched (see also Figure 2c).

Reproducible research and the open sharing of code and data, if not yet commonplace, is also becoming more prevalent (Brunsdon 2016) and such approaches are increasingly an alternative way of working existing next to, or in addition to, more conventional desktop GIS, as evidenced in Arribas-Bel and Reades' (2018) call for a Geographic Data Science.

\section{Building a Critical and Smart symbiosis}

Smart technologies and their implications have received well-deserved critical evaluation. Wyly (2014) fears the co-optation by a 'neo-liberal digital capitalism' and Leszczynski (2018) highlights epistemological limitations of digital methods that are now commonplace when 'smart' datasets are used in academic research. These critiques and worries are well-founded but if taken to heart also highlight a unique opportunity: we can build a different, new vision on the use of technology in Geography, paying particular attention to avoid some of the 
disciplinary mistakes of the last 30 years. Indeed from our own research collaborations across fields of computer science and engineering, we note that quantitative geographers can often be more grounded in and appreciative of social and spatial theories than those coming from outside of Geography.

To do so, we identify two specific points that echo Gahegan's phrase that 'our GIS is too small' (2018). First, on a technical level, as a discipline we need to take charge of building and maintaining our own software platforms. These platforms should be open, accessible and modifiable by the entire academic community and reflect the diversity and heterogeneity of our discipline. Similarly, as data is becoming increasingly commodified, we need to guard against walled data gardens that provide access only to selected researchers. A more widespread adoption of the principles behind reproducible research (Brunsdon 2016) in our research, publishing and teaching would be an important cornerstone in achieving this.

Second, on a more substantive level, the computational approaches we use should allow us to think creatively about geographic processes. We can draw inspiration from all corners of our heterogenous field and its history, and build on top of and together with geographical theory without constraining ourselves by what is possible with off-the-self software. This is especially important for space - one of our core disciplinary concepts. Computational approaches must enable researchers to freely reason with and about spatial processes. If we are to enable an engaged pluralism (Sheppard and Plummer 2007) in Geography, our systems should be designed to allow for contrasting spatial ontologies rather than constrain users to a single perspective on the world.

The history of spatial science shows us that this connection between geographic theory and quantitative methods is indeed possible. We now have the technology and datasets to enable this connection in new, computational ways. To be clear, this is not a Geography in which smart technology and computation completely remove the need for human input. Instead, this is a Geography where social theory and the human intellect, in conjunction with computational technologies, play a key role in analyzing the largest, most versatile and relevant dataset on social space that we have ever had. 


\section{References}

Anderson, Chris. 2008. "The End of Theory: The Data Deluge Makes the Scientific Method Obsolete." WIRED. 2008. http://archive.wired.com/science/discoveries/magazine/1607/pb_theory.

Arribas-Bel, Dani, and Jon Reades. 2018. "Geography and Computers: Past, Present, and Future." Geography Compass 12 (10): e12403. https://doi.org/10.1111/gec3.12403.

Ash, James, Rob Kitchin, and Agnieszka Leszczynski. 2018. “Digital Turn, Digital Geographies?" Progress in Human Geography 42 (1): 25-43.

https://doi.org/10.1177/0309132516664800.

Barnes, Trevor J, and Matthew W Wilson. 2014. "Big Data, Social Physics, and Spatial Analysis: The Early Years." Big Data \& Society 1 (1): 2053951714535365. https://doi.org/10.1177/2053951714535365.

Barrat, A, Marc Barthelemy, R Pastor-Satorras, and A Vespignani. 2004. "The Architecture of Complex Weighted Networks." Proceedings of the National Academy of Sciences 101 (11): 3747-52. https://doi.org/10.1073/pnas.0400087101.

Bergmann, Luke, and David O'Sullivan. 2018. "Reimagining GIScience for Relational Spaces." The Canadian Geographer / Le Géographe Canadien 62 (1): 7-14. https://doi.org/10.1111/cag.12405.

Bergmann, Luke R., and David O’Sullivan. 2017. "Computing with Many Spaces: Generalizing Projections for the Digital Geohumanities and GIScience." In Proceedings of the 1st ACM SIGSPATIAL Workshop on Geospatial Humanities, 31-38. GeoHumanities'17. New York, NY, USA: ACM. https://doi.org/10.1145/3149858.3149866.

Boeing, Geoff. 2018. "A Multi-Scale Analysis of 27,000 Urban Street Networks: Every US City, Town, Urbanized Area, and Zillow Neighborhood." Environment and Planning B: Urban Analytics and City Science, August, 2399808318784595.

https://doi.org/10.1177/2399808318784595.

Boggs, Jeffrey S., and Norma M. Rantisi. 2003. "The 'relational Turn' in Economic Geography." Journal of Economic Geography 3 (2): 109-16.

Brenner, Neil, David J Madden, and David Wachsmuth. 2011. "Assemblage Urbanism and the Challenges of Critical Urban Theory." City 15 (2): 225-40. https://doi.org/10.1080/13604813.2011.568717.

Brunsdon, Chris. 2016. “Quantitative Methods I: Reproducible Research and Quantitative Geography." Progress in Human Geography 40 (5): 687-96. https://doi.org/10.1177/0309132515599625.

Bunge, William. 1966. Theoretical Geography. Royal University of Lund, Dept. of Geography; Gleerup.

Cheng, Tao, James Haworth, and Ed Manley. 2012. "Advances in Geocomputation (19962011)." Computers, Environment and Urban Systems, Special Issue: Advances in 
Geocomputation, 36 (6): 481-87.

https://doi.org/10.1016/j.compenvurbsys.2012.10.002.

Cresswell, Tim. 2013. Geographic Thought: A Critical Introduction. West Sussex: WileyBlackwell.

Delmelle, Elizabeth C. 2017. "Differentiating Pathways of Neighborhood Change in 50 U.S. Metropolitan Areas." Environment and Planning A: Economy and Space 49 (10): 240224. https://doi.org/10.1177/0308518X17722564.

Elwood, S., Lawson, V., \& Sheppard, E. (2017). Geographical relational poverty studies. Progress in Human Geography, 41(6), 745-765.

Forer, Pip. 1978. “A Place for Plastic Space?” Progress in Human Geography 2 (2): 230-67. https://doi.org/10.1177/030913257800200203.

Gahegan, M. 1999. “Guest Editorial: What Is Geocomputation?" Transactions in GIS 3 (3): 2036. https://doi.org/10.1111/1467-9671.00017.

Gahegan, Mark. 2018. "Our GIS Is Too Small.” The Canadian Geographer / Le Géographe Canadien 62 (1): 15-26. https://doi.org/10.1111/cag.12434.

Garrison, William L. 1960. "CONNECTIVITY OF THE INTERSTATE HIGHWAY SYSTEM.” Papers in Regional Science 6 (1): 121-37. https://doi.org/10.1111/j.1435-5597.1960.tb01707.x.

Gatrell, Anthony C. 1981. "Multidimensional Scaling." In Quantitative Geography a British View. Routledge \& Kegan Paul.

Getis, Arthur. 1963. "The Determination of the Location of Retail Activities with the Use of a Map Transformation." Economic Geography 39 (1): 14. https://doi.org/10.2307/142492.

Golledge, Reginald G. 1977. "Multidimensional Analysis in the Study of Environmental Behavior and Environmental Design." In Human Behavior and Environment, 1-42. Boston, MA: Springer US. https://doi.org/10.1007/978-1-4684-0808-9_1.

Golledge, Reginald G, V L Rivizzigno, and Aron Spector. 1976. "Learning about a City: Analysis by Multidimensional Scaling." Spatial Choice and Spatial Behavior, 95-116.

Gould, Peter, and Rodney White. 1974. Mental Maps. New York: Penguin Books.

Graham, Stephen D. N. 2005. "Software-Sorted Geographies." Progress in Human Geography 29 (5): 562-80. https://doi.org/10.1191/0309132505ph568oa.

Hägerstrand, T. 1957. Migration and Area. Migration in Sweden.

Haggett, P, and R J Chorley. 1969. Network Analysis in Human Geography. London: Edward Arnold.

Harris, C D. 1954. "The Market as a Factor in the Localization of Industry in the United States." Annals of the Association of American Geographers 44 (4): 315-48. https://doi.org/10.1080/00045605409352140.

Hartshorne, Richard. 1939. "The Nature of Geography: A Critical Survey of Current Thought in the Light of the Past." Annals of the Association of American Geographers 29 (3): 173. https://doi.org/10.2307/2561063. 
Harvey, D. 1996. Justice, Nature and the Geography of Difference. Wiley-Blackwell.

Harvey, David. 1969. Explanation in Geography. London: Edward Arnold.

Hemmens, G C. 1966. "An Analysis of Urban Travel and the Spatial Structure of Urban Activities." PhD Thesis, Massachusetts Institute of Technology. http://dspace.mit.edu/handle/1721.1/75560.

Jones, Martin. 2009. "Phase Space: Geography, Relational Thinking, and Beyond." Progress in Human Geography 33 (4): 487-506. https://doi.org/10.1177/0309132508101599.

Kendall, David G. 1971. "Maps from Marriages: An Application of Non-Metric Multi-Dimensional Scaling to Parish Register Data." Mathematics in the Archaeological and Historical Sciences, January, 303-18.

Kitchin, Rob M, and Martin Dodge. 2011. Code/Space. Software and Everyday Life. MIT Press. Kitchin, Rob M, and Gavin McArdle. 2016. "What Makes Big Data, Big Data? Exploring the Ontological Characteristics of 26 Datasets." Big Data \& Society 3 (1): 205395171663113. https://doi.org/10.1177/2053951716631130.

Kwan, Mei-Po, and Tim Schwanen. 2009. "Critical Quantitative Geographies." Environment and Planning A 41 (2): 261-64. https://doi.org/10.1068/a41350.

Lally, Nick and Luke Bergmann. Forthcoming. "enfolding: a geographical imagination system (gis)." In: Anna Secor and Paul Kingsbury, eds. Into the Void. Lincoln: University of Nebraska Press.

Lefebvre, H. 1991. The Production of Space. Wiley-Blackwell.

Leszczynski, Agnieszka. 2016. "Speculative Futures: Cities, Data, and Governance beyond Smart Urbanism." Environment and Planning A: Economy and Space 48 (9): 1691-1708. https://doi.org/10.1177/0308518X16651445.

- - . 2018. "Digital Methods I: Wicked Tensions." Progress in Human Geography 42 (3): 47381. https://doi.org/10.1177/0309132517711779.

Marchand, Bernard. 1973. "Deformation of a Transportation Surface." Annals of the Association of American Geographers 63 (4): 507-21. https://doi.org/10.2307/2562056.

Massey, Doreen B. 1994. Space, Place, and Gender. U of Minnesota Press.

Merleau-Ponty, Maurice. (1945) 2012. Phenomenology of Perception. Translated by Donald A. Landes. New York: Routledge.

Nystuen, John D, and Michael F Dacey. 1961. "A Graph Theory Interpretation of Nodal Regions." Papers of the Regional Science Association 7 (1): 29-42. https://doi.org/10.1007/BF01969070.

O'Sullivan, David, Luke Bergmann, and Jim E. Thatcher. 2018. "Spatiality, Maps, and Mathematics in Critical Human Geography: Toward a Repetition with Difference." The Professional Geographer 70 (1): 129-39. https://doi.org/10.1080/00330124.2017.1326081. 
Pebesma, Edzer. 2018. "Simple Features for R: Standardized Support for Spatial Vector Data." The R Journal 10 (1): 439-46.

QGIS Development Team. 2019. “QGIS Geographic Information System. Open Source Geospatial Foundation Project." http://qgis.osgeo.org/.

Rey, Sergio J. 2009. "Show Me the Code: Spatial Analysis and Open Source." Journal of Geographical Systems 11 (2): 191-207. https://doi.org/10.1007/s10109-009-0086-8.

Rey, Sergio J., and Luc Anselin. 2010. "PySAL: A Python Library of Spatial Analytical Methods." In Handbook of Applied Spatial Analysis: Software Tools, Methods and Applications, edited by Manfred M. Fischer and Arthur Getis, 175-93. Berlin, Heidelberg: Springer Berlin Heidelberg. https://doi.org/10.1007/978-3-642-03647-7_11.

Schuurman, Nadine. 2006. "Formalization Matters: Critical GIS and Ontology Research." Annals of the Association of American Geographers 96 (4): 726-39. https://doi.org/10.1111/j.1467-8306.2006.00513.x.

Shelton, Taylor. 2018. "Rethinking the RECAP: Mapping the Relational Geographies of Concentrated Poverty and Affluence in Lexington, Kentucky." Urban Geography 39 (7): 1070-91. https://doi.org/10.1080/02723638.2018.1433927.

Shelton, Taylor, Matthew A Zook, and Alan Wiig. 2015. "The 'Actually Existing Smart City.'” Cambridge Journal of Regions, Economy and Society 8 (1): 13-25. https://doi.org/10.1093/cjres/rsu026.

Sheppard, Eric, and Paul Plummer. 2007. "Toward Engaged Pluralism in Geographical Debate." Environment and Planning A 39 (11): 2545-48. https://doi.org/10.1068/a40205.

Spielman, Seth E, and Jean-Claude Thill. 2008. "Social Area Analysis, Data Mining, and GIS." Computers, Environment and Urban Systems 32 (2): 110-22. https://doi.org/10.1016/j.compenvurbsys.2007.11.004.

Stewart, J Q, and W Warntz. 1958. "Macrogeography and Social Science." Geographical Review 48 (2): 167. https://doi.org/10.2307/212129.

Stratigea, Anastasia, Chrysaida-Aliki Papadopoulou, and Maria Panagiotopoulou. 2015. "Tools and Technologies for Planning the Development of Smart Cities." Journal of Urban Technology 22 (2): 43-62. https://doi.org/10.1080/10630732.2015.1018725.

Taylor, Peter J. 1977. Quantitative Methods in Geography: An Introduction to Spatial Analysis. Boston: Houghton Mifflin.

Thatcher, Jim E., Luke Bergmann, and David O’Sullivan. 2018. "Speculative and Constructively Critical GIS." The Canadian Geographer / Le Géographe Canadien 62 (1): 4-6. https://doi.org/10.1111/cag.12441.

Tobler, W R. 1963. "Geographic Area and Map Projections." Geographical Review, January. http://www.jstor.org/stable/212809. 
Wachsmuth, David, and Alexander Weisler. 2018. "Airbnb and the Rent Gap: Gentrification through the Sharing Economy." Environment and Planning A: Economy and Space 50 (6): 1147-70. https://doi.org/10.1177/0308518X18778038.

Wyly, Elvin. 2011. "Positively Radical." International Journal of Urban and Regional Research, April, no-no. https://doi.org/10.1111/j.1468-2427.2011.01047.x.

- - . 2014. "The New Quantitative Revolution." Dialogues in Human Geography 4 (1): 26-38. https://doi.org/10.1177/2043820614525732. 